\title{
Prevalence of bifid mandibular canals by cone beam computed tomography
}

\author{
Maria Fernanda Lima Villaça-Carvalho ${ }^{1}$ - Luiz Roberto Coutinho Manhães $\mathbf{J r}^{2}$ • \\ Mari Eli Leonelli de Moraes ${ }^{2}$ - Sérgio Lúcio Pereira de Castro Lopes ${ }^{2}$
}

Received: 23 February 2016 / Accepted: 27 June 2016 / Published online: 15 July 2016

(C) Springer-Verlag Berlin Heidelberg 2016

\begin{abstract}
Purpose The aim of this study was to evaluate the prevalence of bifid mandibular canals (BMC) by cone beam computed tomography (CBCT).

Materials and methods We examined CT scans from 300 patients both male and female, aged 25 to 87 years. The subjects were divided into groups according to gender, male group (MG) and female group (FG) as well as subgroups according to the side, right $(\mathrm{R})$ and left $(\mathrm{L})$. Tomographic acquisitions were performed on the device I-Cat ${ }^{\circledR}$ Classic. Image analysis was performed on the XoranCat ${ }^{\circledR}$ software of the equipment itself, aided by image filters associated with transverse, oblique, and panoramic reconstruction cuts for analysis of the BMC. The results were displayed as descriptive analysis of the values and comparisons between factors were performed using ANOVA at a significance level of $95 \%$.

Results BMC was observed in 80 cases $(26.67 \%)$, of which, $39(48.75 \%)$ were in males and $41(51.25 \%)$ in females; no
\end{abstract}

Maria Fernanda Lima Villaça-Carvalho

mfervillaca@hotmail.com

Luiz Roberto Coutinho Manhães, Jr

manhaes@fosjc.unesp.br

Mari Eli Leonelli de Moraes

eli@fosjc.unesp.br

Sérgio Lúcio Pereira de Castro Lopes

sergio.lopes@fosjc.unesp.br

1 Oral Pathology, Instituto de Ciência e Tecnologia - UNESPUniversidade Estadual Paulista Júlio de Mesquita Filho - São José dos Campos, Av. Eng. Francisco José Longo, ${ }^{\circ} 777$ Jardim São Dimas, São José dos Campos 12245-000, SP, Brazil

2 Oral Radiology, Instituto de Ciência e Tecnologia-UNESP, São José dos Campos, SP, Brazil difference was seen between genders, neither by affected side, although the right side was more frequently affected (66.67\%) when both genders were combined.

Conclusion The prevalence of BMC is significant and should not be overlooked.

Keywords Bifid mandibular canal $\cdot$ Cone beam computed tomography $\cdot$ Mandibular nerve $\cdot$ Anatomic variation

\section{Introduction}

Surgical procedures involving structures adjacent to the mandibular canal require accurate knowledge of the intraosseous trajectory of this anatomical landmark in order to avoid iatrogenic injuries to this site. Prior to installation of implants in the jaw, for example, clinicians should request the measurement of distances around the main mandibular canal [7].

Procedures such as osteotomy, bone remodeling, and implant placement carry a risk of injury to the mandibular canal, which can result in transient or permanent paresthesia [17]. In general, the mandibular canal appears as a single conduit; however, in some cases, the presence of an accessory canal can be identified, known as bifid. According to Langard et al. (1989) [10], the mandibular canal can vary in shape such as oval, circular, or pear-shaped. Many dental surgeons are unaware of the existence of such anatomical variability and are unable to view it on panoramic radiographs. As a result, trans- and postoperative surgical complications as well as failures in implant placement can occur, which could have been prevented should such anatomical variation been identified [19].

Panoramic radiographs (PR) can be used to assess bone height and horizontal distances; however, image magnification must be taken into account both horizontally and vertically. When these distances are critical for treatment planning, 
computed tomography (CT) should be performed in order to overcome the limitations relating to the two-dimensional image provided by panoramic and intraoral radiographs. The location of the mandibular canal, maxillary sinus, nasal cavity as well as the angle of the alveolar crest and, in particular, bone volume are prerequisites for proper surgical planning [13].

Many types of bifid mandibular canals (BMC) can be described and classified according to anatomical location and configuration using panoramic radiographs. Some studies, however, suggest that CT $[9,18,22]$ should be the gold standard for this purpose, since for Rouas et al. (2007) [23], conventional radiography can only suggest the presence of a $\mathrm{BMC}$, but cannot confirm it. Cone beam computed tomography (CBCT) has been used in dentistry because of its significantly lower radiation dose compared to multislice CT [22].

Therefore, the purpose of this study was to evaluate the prevalence of BMC by CBCT in order to highlight its importance when planning surgical treatment.

\section{Method}

This research was approved by the Ethics Committee in Research of the Faculty of Dentistry of São José dos Campos Júlio de Mesquita Filho-UNESP, protocol number 071/2011, according to Resolution Number 196/96.

\section{Sample}

The sample included 598 CT scans from the archives of a private clinic in São José dos Campos, of which 300 were selected for analysis. The sample comprised both males and females, aged between 25 and 87 years, who underwent tomographic examination in 2010. Ethnicity and type of edentulous jaws were not considered for sample selection. Patients were divided into male group (MG) and female group (GS), including a subdivision according to side, right (R), left (L).

The inclusion criterion was all CT images from patients who underwent examination of the mandible. The exclusion criteria were images of the maxilla only, CT images with poor quality, images from patients with a history of trauma or lesions in the lower arch, and orthognathic or reconstructive surgery in the posterior aspect of the mandible.

\section{Tomographic image acquisition}

All imaging was performed on the Classic I-Cat ${ }^{\mathrm{TM}}$ (Imaging Sciences Internation, Hatchfield, PA, USA) with standard $0.25 \mathrm{~mm}$ voxel, field of view (Fov) of $13 \mathrm{~cm}$, length of acquisition of 40 pulsatile seconds, and useful radiation of $6.6 \mathrm{~s}$, according to the manufacturer's standards. The factors used for image acquisition were pre-established by the equipment working at a fixed $120 \mathrm{kV}$ and varying 5:07 mA, according to the resolution used. All images were processed and edited on XoranCat $^{\mathrm{TM}}$ (Xoran Technologies, Ann Arbor, MI, USA).

\section{CT scans analysis}

Prior to analysis, the tomographic images were corrected for anatomical planes under the multiplanar reconstruction (MPR) page of the XoranCat ${ }^{\circledR}$ software (Xoran Technologies, USA).

An appropriately trained and experienced specialist radiologist performed the analysis of the $\mathrm{CT}$ images in order to identify BMC. Using the axial section (0.25-mm thickness), a cutting plane was traced along the alveolar ridge in order to construct the panoramic image and the cross sections. The cross sections were standardized at $1-\mathrm{mm}$ thick and $1-\mathrm{mm}$ apart. For the panoramic reconstruction, a $5.25-\mathrm{mm}$ thick slice was used, as shown in Fig. 1.

Minor modifications to the alveolar ridge cutting plane as well as corrections for brightness and contrast and image filters were necessary to improve visualization of the mandibular canal, since its trajectory is not linear and must be individualized for each side of the mandible. Whenever bifid canals were detected, oblique cuts were obtained in the buccolingual direction.

When BMC were present, two measurements were taken using a modification to the Lofthag-Hansen Method (2009) [5]: one between the mandibular canal and the edge of the alveolar bone ridge and another from the BMC to the same reference point. A subtraction between these measurements was performed to compare the distances (Fig. 2). Neglecting such measurements could increase the risk of injury to the alveolar nerve, for example, during dental implant placement.

\section{Statistical analysis}

Descriptive analysis of the values was displayed as absolute (n) and relative numbers (\%). The comparisons between genders, sides, and full sampling were performed using ANOVA at a $95 \%$ significance level.

\section{Results}

The trajectory of the mandibular canal was found to be normal in 220 of the 300 CBCT analyzed, representing $73.33 \%$ of the sample, from which 137 were images from females and 83 from males. The remaining 80 patients $(26.67 \%)$ exhibited anatomic variations (41 females and 39 males).

Regarding the 80 cases with BMC, female patients were slightly more affected $(n=41,51.25 \%)$ than males $(n=39$, $48.75 \%)$. When male patients were studied alone, 26 (66.67\%) had a BMC on the right side, while 13 (33.33\%) had it on the left. The mean values and standard deviations of the difference between the distance from the mandibular canal to the alveolar ridge and the bony border of the bifid canal to 


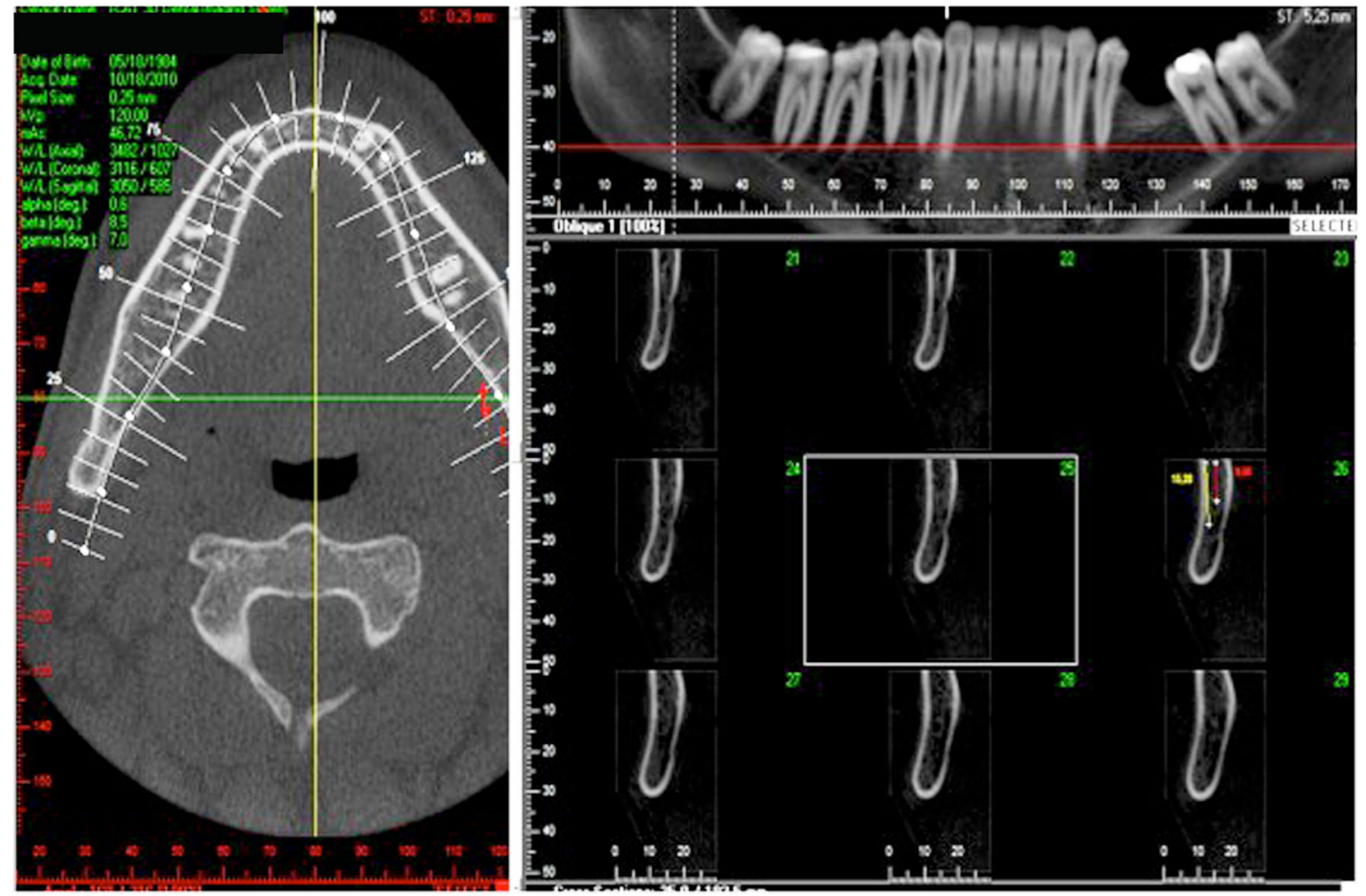

Fig. 1 Tomographic image of the axial plans, cross sections, and panoramic image acquisition screen

the alveolar ridge are shown in Table 1. Of the 41 female BMC cases, 24 (58.54\%) occurred on the right side and 17

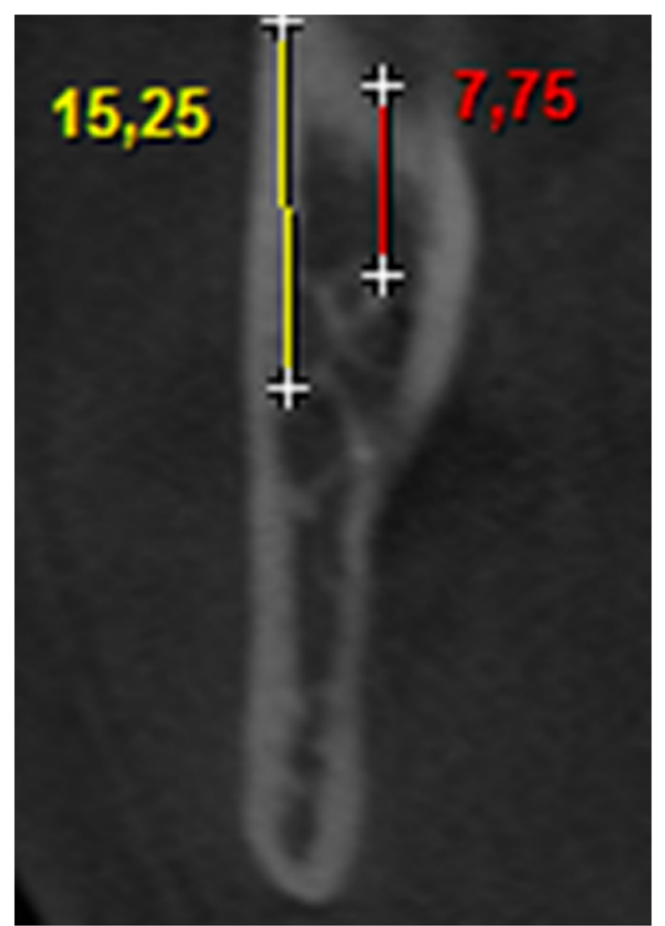

Fig. 2 Cross section indicating the presence of BMC; measurements taken from the top of the bone crest to the top of the bifid canal ridge as well as to the top of the main canal. Measured from the top of the alveolar ridge to the top of the main canal (yellow). Measured from the top of the alveolar ridge to the top of the accessory canal (red)
$(41.46 \%)$ on the left. The mean values and standard deviations of the difference between the distance from the mandibular canal to the alveolar ridge and the bony border of the bifid canal to the alveolar ridge are shown in Table 2.

Comparisons relating to the presence of $\mathrm{BMC}$ for both genders and side revealed no significant difference.

\section{Discussion}

The mandibular canal is a bony canal that originates at the mandibular foramen and terminates at the mental foramen. The trajectory of the inferior alveolar artery, vein, and nerve passes through this conduit. The mandibular canal is generally accepted as an anatomic structure of extreme importance in clinical practice and the knowledge of its location is crucial for successful mandibular surgical procedures $[3,9,18,27]$. The mandibular canal is normally a single conduit; however, when the presence of a second canal is identified, it is referred to as bifid. Studies have shown that BMC are not commonly seen, which means that many dentists are unaware of the existence of anatomical variations, hence, failing to identify them in panoramic radiographs $[11,17,24]$.

The advantages and limitations of PR have been well described in the literature $[20,26]$. According to Peltola and Mattila (2004) [20], PR can provide a wide range of information regarding anatomic structures and pathological changes. However, on its own, it does not provide information on three- 
Table 1 Number and respective percentages of BMCs in males; measurements from the top of the alveolar ridge to the top of the mandibular canal (mean, standard deviation, minimum, median, maximum)

\section{Male}

\begin{tabular}{lllllll}
\hline Side & Number (\%) & Average & SD & Min & Median & Max \\
\hline Right & $26(66.67)$ & 4.635 & 2.066 & 0.900 & 4.380 & 8.210 \\
Left & $13(33.33)$ & 4.425 & 2.696 & 1.520 & 3.990 & 10.020 \\
Total & $39(100.00)$ & 4.565 & 2.261 & 0.900 & 4.250 & 10.020 \\
\hline
\end{tabular}

dimensional structures. Other authors $[13,25]$ have also emphasized the value that a dental radiograph can provide, with panoramic radiographs described as important tools for assessing the alveolar bone and noble structures, yet corroborate its limitations in terms of their two-dimensional image. Therefore, tomographic images are indicated, owing to their ability to provide sufficient detail to estimate vertical and horizontal dimensions, while allowing an improved view of bony defects and anatomical structures, which are crucial for surgical planning. Other authors have recommended the use of panoramic radiographs for preoperative assessment; however, due to the aforementioned disadvantages, studies have suggested a combination of the conventional panoramic view with other imaging techniques, such as $\mathrm{CT}$ should be preferred in order to ensure a more accurate diagnosis $[5,12,21,26]$.

When compared with CT, CBCT provides images of similar quality that enable visualization of structures at high contrast $[15,17]$; while also allowing evaluation of the amount of bone and the presence of possible bone graft donor sites, as well as detecting, with high accuracy and precision, the location of important structures such as the mandibular canal and maxillary sinus, which aids in the decision of implant placement [2].

Due to the aforementioned advantages of CBCT over PR, the present study used CBCT imaging to assess the prevalence of BMC. Correr et al. (2013) [3] aimed to classify the morphology of BMC and evaluate its relationship with the roots of third molars, using CBCT, as per Rouas et al. [23] who reported that this scan is better than PR for detection and analysis of $\mathrm{BMC}$. Other studies have shown that the incidence of BMC is less than $1 \%$ when viewed in panoramic radiographs $[9,18$, 26]. Conversely, when using $\mathrm{CBCT}$, the incidence is

Table 2 Number and respective percentages of BMCs in females; measurements from the top of the ridge to the top of the mandibular canal (mean, standard deviation, minimum, median, maximum)

Female

\begin{tabular}{lllllll}
\hline Side & Number (\%) & Average & SD & Min & Median & Max \\
\hline Right & $24(58.54)$ & 4.067 & 2.327 & 1.250 & 4.000 & 11.810 \\
Left & $17(41.46)$ & 5.240 & 2.650 & 0.800 & 5.260 & 11.250 \\
Total & $41(100.00)$ & 4.555 & 2.500 & 0.800 & 4.240 & 11.810 \\
\hline
\end{tabular}

significantly higher, ranging from 15.6 to $65 \%[4,8,15]$. However, Neves et al. (2013) [16] reported the incidence of BMC as $7.4 \%$ (19 cases) using panoramic radiographs and $9.8 \%$ ( 25 cases) for CBCT imaging, yet no significant difference was found between the two methods; therefore, formulating the conclusion that panoramic radiographs can aid in the detection of anatomical variations of BMC.

Orhan et al. (2011) [19], as with the present study, aimed to identify BMC using CBCT imaging, only in the Turkish adults as opposed to the Brazilian population. The authors evaluated images from both sides of 242 patients. Bifid canals were found in $46.5 \%$ of the patients, suggesting an underestimation of BMC. This may be due to the use of conventional radiography in previous studies such as by Carter and Keen (1971) [1] and Rossi et al. (2009) [22], in which, this anatomical variant was found in $25 \%$ of cases and $34.9 \%$ respectively, which is more in keeping with the values obtained in this study (26.67\%), and that of Fu et al. (2013) [6] (30.6\%), the latter assessing prevalence of BMC using multislice CT.

As in previous studies $[8,9,15]$, a slightly higher prevalence of BMC being found in the female population of this study, however, a significant difference was not observed (51.25\%). Nevertheless, a recent Taiwanese study [1] using multislice CT reported a higher prevalence of BMC in males and concluded that the gender difference was more likely associated to the population studied rather than type of imaging.

In the current study, when one considers the BMC cases in male patients, a higher occurrence was observed on the right (66.67\%) than the left side (33.33\%); a situation that was also common to the female participants, with $58.54 \%$ of BMC being found on the right and $41.46 \%$ on the left side. Though relevant, these values were not statistically significant. Corroborating these data, Fu et al. (2013) [6] also reported a higher prevalence of $\mathrm{BMC}$ on the right side and suggested that these adults may in fact chew on the right side; however, an exact explanation remains uncertain. Meanwhile, the prevalence of BMCs seen on panoramic images in Mohammad et al. (2015) [14] study of 5000 radiographs was $1.2 \%$ and was not correlated with age or gender.

In this study, which used CBCT imaging, measurements were taken from the top of the alveolar ridge to the top of the mandibular canal, with the intention of investigating the possible presence of bifid canals. Lofthag-Hansen et al. (2008) [13] also aimed to evaluate visibility of the mandibular canal and, as in the present study, performed measurements from the top of the canal to the top of the marginal bone via CBCT. The authors suggested that $\mathrm{CBCT}$ imaging should be the gold standard for implant planning in the posterior mandible.

Knowledge of anatomy and anatomical variations of the mandibular canal are essential for successful surgical procedures; it is therefore crucial that these variations be identified, in order to prevent complications [3]. In this study, as corroborated by others $[3,4,8,15,19]$, CBCT has shown itself to be 
suitable for adequate assessment of this anatomic variation, due its high resolution allowing a detailed identification of the structure of interest.

\section{Conclusion}

This study allows one to conclude that the prevalence of BMC is significant, with a higher occurrence on the right side. No difference in prevalence for gender was observed. Additionally, dentists should not neglect its presence.

Compliance with ethical standards This research was approved by the Ethics Committee in Research of the Faculty of Dentistry of São José dos Campos Júlio de Mesquita Filho-UNESP, protocol number 071/ 2011, according to Resolution Number 196/96.

Conflict of interest To the Publishing Commission of the Oral and Maxillofacial Surgery

The authors Maria Fernanda Lima Villaça-Carvalho, Luiz Roberto Coutinho Manhães Júnior, Mari Eli Leonelli de Moraes, and Sérgio Lúcio Pereira de Castro Lopes hereby submit the original manuscript entitled Prevalence of bifid mandibular canals by cone beam computed tomography to the Oral and Maxillofacial Surgery, represented by the Journal's Publishing Commission. The authors certify that said manuscript is original and does not infringe any patent, trademark, copyright, trade secret rights, or any other proprietary rights of third parties and that is no confict of interest.

The authors also declare that, except where explicitly disclosed, they have no financial interest or agreement with any entity that may be perceived as bearing on the objectivity of the manuscript, unless said financial interest or agreement has been disclosed in writing to the Oral and Maxillofacial Surgery, in a separate document, signed by all authors.

The authors further declare that the study, whose results are reported in the manuscript, was performed in compliance with the current policies of the institutions to which the authors are affiliated, related to the use of animal and/or human subjects, and/or animal- or human-derived material (Institutional Ethics Committee approval).

The authors agree to indemnify the Oral and Maxillofacial Surgery and to hold the Oral and Maxillofacial Surgery harmless from any claims, costs, lawyers' fees, indemnity, or license fees incurred by the Surgical and Radiologic Anatomy as a result of any claim of infringement of rights, or of any violation of Institutional Ethics Committee compliance, arising in whole or in part from publication of the manuscript.

\section{References}

1. Carter RB, Keen EM (1971) The intramandibular course of the inferior alveolar nerve. J Anat 108(12):433-440

2. Cavalcanti MGP, Sales MAO. TC (2008) Diagnóstico por Imagem da Face. Livraria Editora Santos, São Paulo

3. Correr GM, Iwanko D, Leonardi DP, Ulbrich LM, de Araújo MR, Deliberador TM (2013) Classificationof bifidmandibular canals using cone beam computed tomography. Braz Oral Res 27(6): $510-516$

4. de Oliveira-Santos C, Souza PH, de Azambuja Berti-Couto S, Stinkens L, Moyaert K, Rubira-Bullen IR, Jacobs R (2012)
Assessment of variations of the mandibular canal through cone beam computed tomography. Clin Oral Investig 16(2):387-393

5. Frederiksen NL (1995) Diagnostic imaging in dental implantology. Oral Surg 80(5):540-554

6. Fu E, Peng M, Chiang CY, Tu HP, Lin YS, Shen EC (2012) Bifid mandibular canals and the factors associated with their presence: a medical computed tomography evaluation in a Taiwanese population. Clin Oral Implants Res 25(2):e64-e67

7. Kamburoglu K, Kiliç C, Ozen T, Yuksel SP, Turkey A (2009) Measurements of mandibular canal region obtained by cone-beam computed tomography: a cadaveric study. Oral Surg Oral Med Oral Pathol Oral Radiol Endod 107(2):34-42

8. Kuribayashi A, Watanabe H, Imaizumi A, Tantanapornkul K, Kurabayashi T (2010) Bifid mandibular canals: cone beam computed tomography evaluation. Dentomaxillofac Radiol 39(4): 235-239

9. Langlais RP, Broadus R, Glass BJ (1985) Bifid mandibular canals in panoramic radiographs. J Amer Dent Ass 110(6):923-926

10. Langland OE, Langlais RP, McDadid WD, DelBalso A (1989) Panoramic radiology, 2nd edn. Lea\&Febiger, Philadelphia

11. Lew K, Townser G (2006) Failure to obtain adequate anesthesia associated with a bifid mandibular canal: a case report. Aust Dent J 51(1):86-90

12. Lindh C, Peterson A (1989) Radiologic examination for location of the mandibular canal: a comparison between PR and conventional tomography. Int $\mathrm{J}$ Oral Maxillofac Implants 4(3):249-253

13. Lofthag-Hansen, Grondahl K, Ekestube A (2009) Cone-beam CT preoperative implant planning in the posterior mandible: visibility of anatomic landmarks. Clin Implant Dent Relat Res 11(3):246-255

14. Motamedi MHK, Navi F, Sarabi N (2015) Bifid mandibular canals: prevalence and implications. J Oral Maxillofac Surg 73:387-390

15. Naitoh M, Nakahara K, Suenaga Y, Gotoh K, Kondo S, Ariji E (2010) Comparison between cone-beam and multislice computed tomography depicting mandibular neurovascular canal structures. Oral Surg Oral Med Oral Pathol Oral Radiol Endod 109(1):25-31

16. Neves FS, Nascimento MC, Oliveira ML, Almeida SM, Bóscolo FN (2014) Comparative analysis of mandibular anatomical variations between $\mathrm{PR}$ and cone beam computed tomography. Oral Maxillofac Surg 18(4):419-424

17. Niek L, Gerlach MD, Gert J, Thomas JJ, Frits A (2010) Reproducibility of 3 different tracing methods based on cone beam computed tomography in determining the anatomical position of the mandibular canal. J Oral Maxillofac Surgery 68(4):811-817

18. Nortjé CJ, Farman AG, Grotepass FW (1977) Variations in the normal anatomy of the inferior dental (mandibular) canal: a retrospective study of panoramic radiographs from 3612 routine dental patients. Br J Oral Surg 15(1):55-63

19. Orhan K, Aksoy S, Bicenoglu B, Sakul BU, Paksoy CS (2011) Evaluation of bifid mandibular canals with cone beam computed tomography in a Turkish adult population: a retrospective study. Surg Radiol Anat 33(6):501-507

20. Peltola JS, Mattila (2004) Cross-seccional tomograms obtained with four panoramic radiographic units in the assessment of implant site measurements. Dentomaxillofac Radiol 33(5): 295-300

21. Reiskin AB (1998) Implant imaging status, controversies and new developments. Dent Clin North Am Philadelphia 42(1):47-56

22. Rossi P, Brucker MR, Rockenbach MIB (2009) Canais mandibulares bifurcados: análise em radiografias panorâmicas. Ciênc Méd 18(2):99-104

23. Rouas P, Nancy J, Bar D (2007) Identification of double mandibular canals: literature review and three case reports with CT scans and cone beam CT. Dentomaxillofac Radiol 36(1):34-38 
24. Sanchis JM, Peñarrocha M, Soler F (2003) Bifid mandibular canal. J Oral Maxillofac Surg 61(4):422-424

25. Shiratori LN, Marotti J, Yamanouchi J, Chilvarquer I, Contin I, Tortamano-Neto P (2012) Measurement of buccal bone volume of dental implants by means of cone-beam computed tomography. Clin Oral Implants Res 23(7):797-804
26. Sonick M, Abrahams J, Faiella RA (1994) A comparison of the accuracy of periapical, panoramic and computed tomographic radiographs in locating the mandibular canal. Int Oral Maxillofac Implants 9(4):455-460

27. Xie Q, Wolf J, Soikkonen K, Ainamo A (1996) Height of mandibular basal bone in dentate and edentulous subjects. Acta Odontol Scand 54(6):379-383 